$13 \int_{0}^{179}$

MUSTER UC. 20

AN APPLIC/TION OF A METHOD

FOR COMPARTIG ONEDIMIENSIONAL

AND TWOYTRMENSHONAL MODELS O'f A GROUMD.WTER FLOW SYSTEM 。
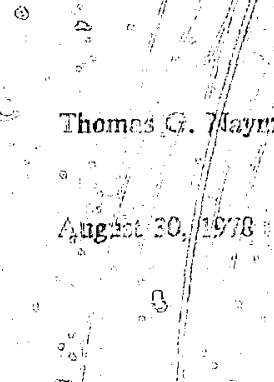

This work was supported by the U.S. Nuclear Regulatory Commission Unider Interegency Agroentent DOE 40.550-75 with the U.S. Department of Enorgy,

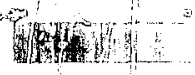
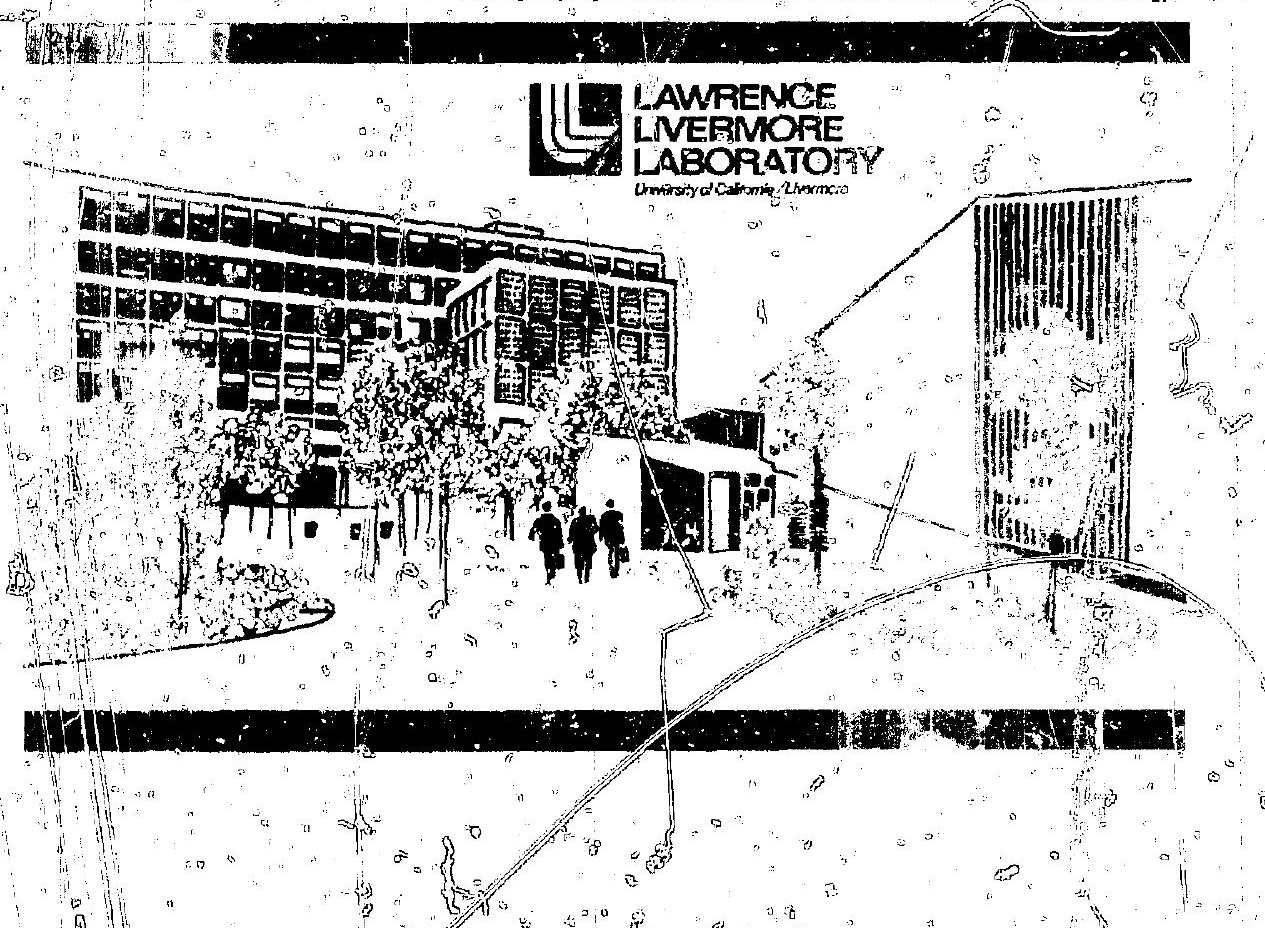

LAWPENGE LNERMORE LABORATOTYY

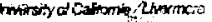

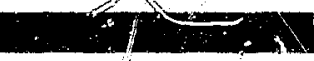




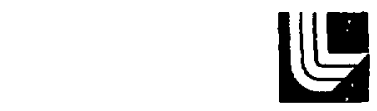

LAWRENCE LIVERMORE LABORATORY

University of Cattornia Livernore, California 94550

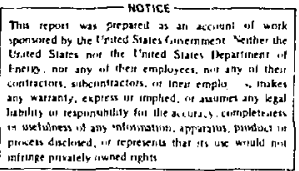

\section{UCAL-52541 \\ AN APPLICATION OF A METHOD FOR COMPARING ONE-DIMENSIONAL AND TWO-DIMENSIONAL MODELS OF A GROUND-WATER FLOW SYSTEM}

Thomas G. Naymik

MS. date: August 30, 1978 
FOREWORD

Work supported by the U.S. Nuclear Regulatory Commission, office of Waste Management under Interagency Agreement DOE 40-550-75 with the U.S. Department of Energy. 
consents

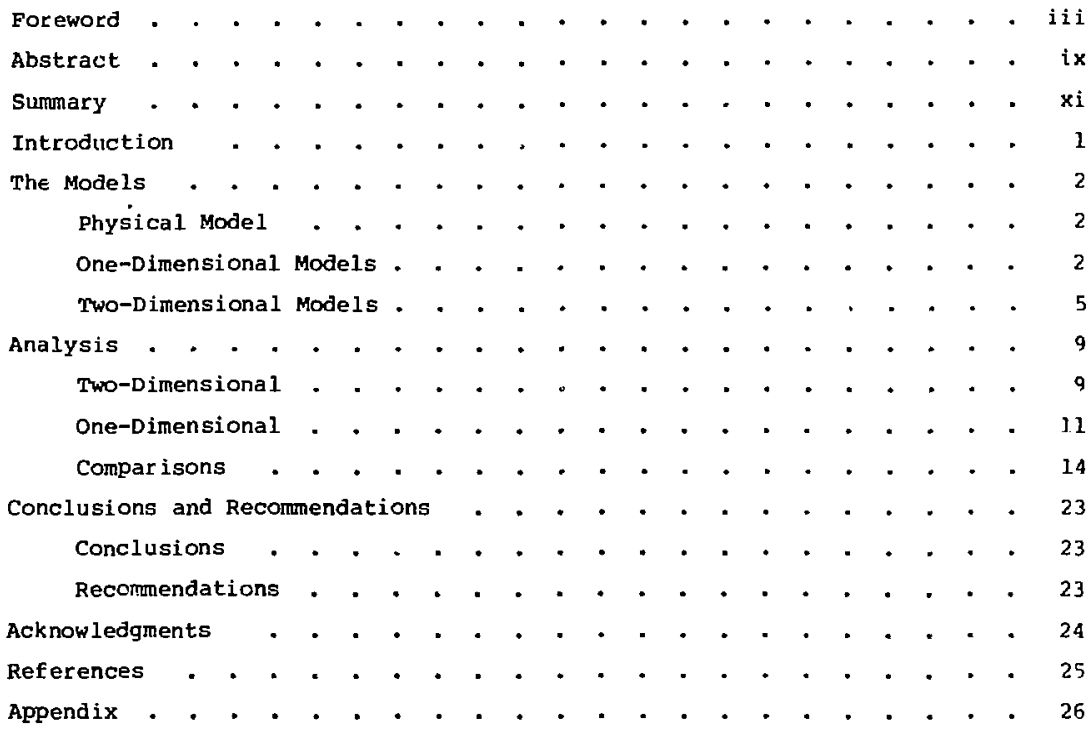




\section{LIST OF ILLUSTRATIONS}

1. The physical model of a nuclear waste depository in geologic media . . . . . . . . . . . . . . . . . . . . . . 3

2. The one-dimensional flow path model . . . . . . . . . . . . 4

3. The finite element mesh cross-sectional view with ti.e 1-D node

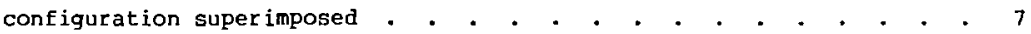

4. The fracture zones surrounding the manmade features represented by two layers of element strings above and below backfill material . . . 8

5. Cross-sectional areas of $1-D^{\prime}$ calculated from $x$ and $z$ values of 2-D and $y$ values of the physical model . . . . . . . . . . . 13

6. Equipotentials of the steady-state ground-water system in the preexcavation state . . . . . . . . . . . . . . . 14

7. Equipotentials of the steady-state flow regime (2-D) when $K$ of the depository and tunnel fracture zones equals $0.1 \mathrm{~cm} / \mathrm{s}$ and $\mathrm{K}$ of the

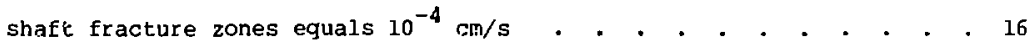

8. Equipotentials of the steady-state flow regime (2-D) when $k$ of the depository and tunnel. fracture zones equals $0.01 \mathrm{~cm} / \mathrm{s}$ and $k$ of the

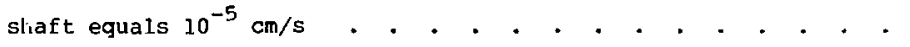

9. Equipotentials of the steady-state flow regime (2-D) when $k$ of the depository and tunnel fracture zones equal $10^{-2} \mathrm{~cm} / \mathrm{s}$ and $\mathrm{K}$ of the shaft fracture zones equals $10^{-5} \mathrm{~cm} / \mathrm{s}$. . . . . . . . . . . 17

10. Flow through the depository fracture zone between nodes 1 and 2 . . 18

11. Flow through the tunnel fracture zone between nodes 2 and 4 . . . 19

12. Flow through the shaft fracture zone in the depository bed between nodes 4 and 5 . . . . . . . . . . . . . . . . . . . . 19

13. Flow through the shaft fracture zone in the barrier bed between nodes 5 and 6 . . . . . . . . . . . . . . . . . . . 20

14. Flow through the geologic media above the depository between nodes 1,3 , and 6 
A-1. The conductivities of the fracture zones are 100 times greater than the preferred values . . . . . . . . . . . . . . 26

A-2. The conductivities of the fracture zones are 10 times greater than the preferred values . . . . . . . . . . . . . . 27

A-3. The conductivities of the fracture zones equal the preferred values . . . . . . . . . . . . . . . . . . . . 27

A-4. The conductivities of the fracture zones are 10 times less chan

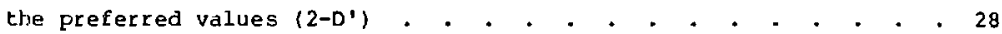

A-5. The conductivities of the fracture zones are 100 times less than

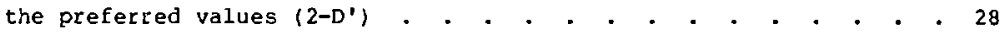




\section{LIST OF TABLES}

1. Lengths and cross-sectional areas of the 1-D model segments . . . 5

2. The initial and preferred values of hydraulic conductivity and porosity used in the 1-D and 2-D models . . . . . . . . . . . . 6

3. Preferred cross-sectional areas (1-D) compared to modified (1-D')

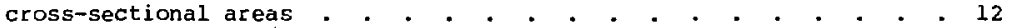

4. Hydraulic corductivities assigned to the fracture zones surrounding the depository, tunnel, and shaft . . . . . . . . . . . . 15 
To evaluate the inability of a one-dimensional ground-water model to interact continuously with surrounding hydraulic head gradients, simulations using one-dimensional and two-dimensional ground-water flow models were compared. This approacu used two types of models:

- Flow-conserving one-and-two dimensional models.

- One-dimensional and two-dimensional models designed to yield two-dimensional solutions. The hydraulic conductivities of controlling features were varied and model comparison was based on the travel times of marker particles. The solutions within each of the two model types compare reasonably well, but a three-dimensional solution is required to quantify the comparison. 


\section{SUMMARY}

A method was applied to examine the implications of the noninteractive assumption of a one-dimensional model of ground-water flow. Four models were used in the study. Two of the models, a referenced one-dimensional model and a two-dimensional model with weighted conductivities and porosities attempted to conserve flow. The other two models used were a two-dimensional, standard cross-sectional model and $a$ one-dimensional model having enlarged cross-sectional areas designed to yield two-dimensional solutions.

The solutions of the flow conserving models compared well with each other with respect to plots of travel time. The same was true of the large cross-section models. However, a three-dimensional solution will be necessary to quantify comparisons. 


\section{INTRODUCTION}

One-dimensional (1-D) ground-water models have value in studies requiring several iterative simulations (e.g. sensitivity analyses). The flexibility of a $[1-n)$ model is an additional asset. On the other hand, 1-D yround-water models cannot react continuously with the surrounding hydrologic environment. Therefore, flow paths must initially be assumed in the design of 1-D models. Results from 1-D models should be compared with higher order models to test. the effects of the assumed flow paths on model performance. In this paper, 1-D and 2-D models are compared after applying them to a physical model. 
PHYSICAL MODEL

A physical model was developed for evaluating important technical factors at a nuclear waste depository in geologic media. ${ }^{l}$ It consists of six horizontal strata with the depository constructed in the layer of lowest hydraulic conductivity (Fig. 1). The strata (vertically down from the surface) are: a confining surface layer, an aquifer, an aquiclude (upper barrier bed), a lay'r of low conductivity (depository bed), an aquiclude (lower barrier bed), and an aquifer. The preexcavation hydrologic regime throughout the strata includes a horizontal hydraulic head gradient of 0.005 and a positive artesian head of $60 \mathrm{~m}$ between the top of the lower aquifer and the bottom of the upper aquifer. Therefcre, the ground-water flow vectors thcough the depository bed and barrier beds have a significant upward component. The postexcavation hydrologic regime is controlled predominantly by manmade fracture zones surrounding the depository, tunnel, and shaft.

ONE-DIMENSIONAL MODEL

The 1-D model (Fig. 2) was designed ${ }^{1}$ to approximate the postexcavation ground-water flow paths. Darcy's equation was used to calculate the flow rate through the various segments of the 1-D model:

$$
Q=\frac{K\left(h_{1}-h_{2}\right) A}{L}
$$

where

$$
\begin{aligned}
\mathbf{Q} & =\text { volume flow rate } \\
\mathbf{R} & =\text { hydraulic conductivity } \\
\mathbf{h}_{1}-\mathbf{h}_{2} & =\text { hesd loss over distance } \mathrm{L} \\
\mathbf{L} & =\text { distance in the direction of flow } \\
\mathbf{A} & =\text { eross-sectional area of flow. }
\end{aligned}
$$




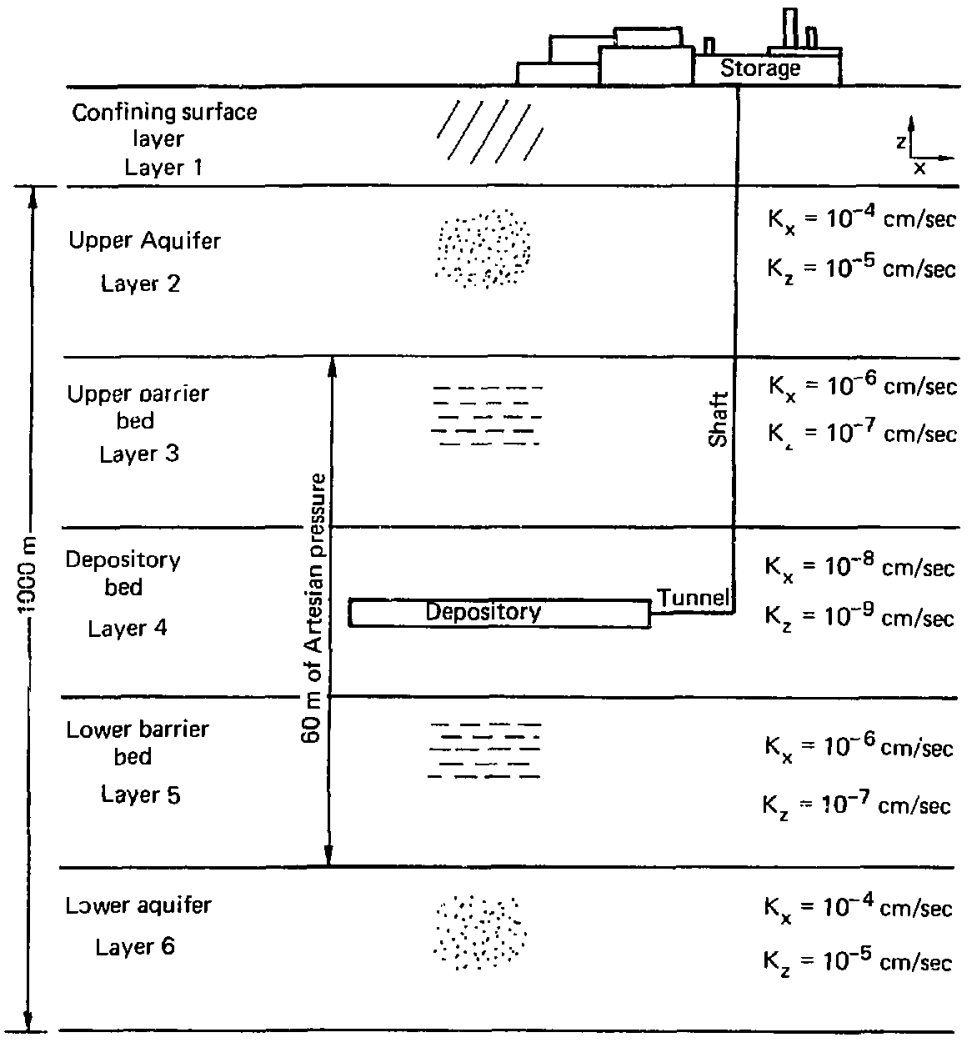

FIG. 1. The physical model of a nuclear waste depository in geologic media Modified from Dayem et al. 1977). 
Confining layer

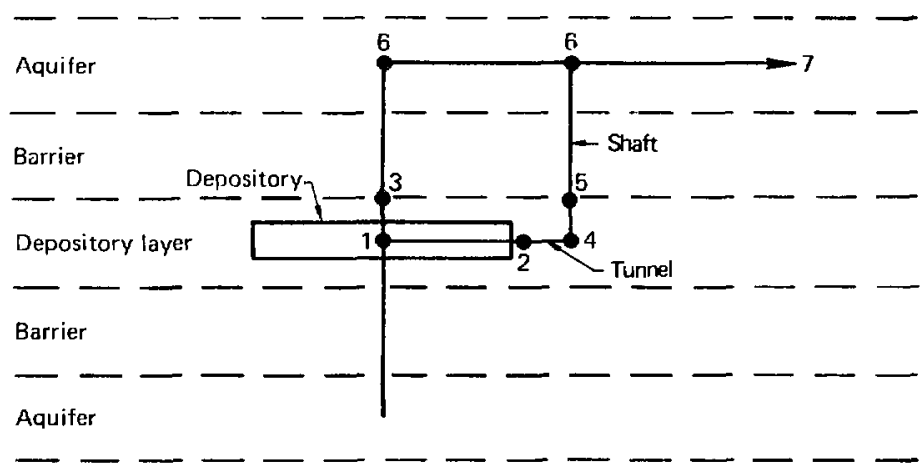

FIG. 2. The 1-D flow-path model. Note: 1-D node configuration used to simulate flow from the depository consists of two pathways: on through the man-made fractures nodes ( 1 to 2 to 4 to 5 to 6 to 7 ) and one through the geologic media (1 to 3 to 6 to 7 ). Two nodes are labeled 6 because both of them have a defined artesian head of 0.0 . The horizontal hydraulic gradient betweer them was neglected (modified from Holdsworth, et al., 1977). I 
Table 1 contains the dimensions or the 1-D flow model. The directions of ground-water flow were initially assumed. The solutions of the 1-D model were then cripared to solutions derived from a two-dimensional model of the same physical system.

TABLE 1. Lengths and cross-sectional areas of the 1-D model segmencs.

\begin{tabular}{|c|c|c|}
\hline Feature & $\begin{array}{l}\text { Length } \\
\text { of } \\
\text { segment, m }\end{array}$ & $\begin{array}{c}\text { Cross-sectional } \\
\text { area of segment, } \\
\mathrm{m}^{2} \\
\end{array}$ \\
\hline Layers $2,3,4,5,6$ & $200 \mathrm{~m}$ thick & \\
\hline Depository, nodes $1 \rightarrow 2$ & 1200 & 316 \\
\hline Tunnel, nodes $2+4$ & 440 & 18.96 \\
\hline Shaft, nodes $4+5$ & 100 & 10 \\
\hline Shaft, nodes $5+6$ & 200 & 5 \\
\hline $\begin{array}{l}\text { Layer } 4 \text { above depository } \\
\text { nodes } 1+3\end{array}$ & 100 & $5 \times 10^{6}$ \\
\hline $\begin{array}{l}\text { Layer } 3 \text { above depcisitory } \\
\text { nodes } 3+6\end{array}$ & 200 & $5 \times 10^{6}$ \\
\hline Layer 2, nodes $6+7$ & 16000 & $4 \times 10^{6}$ \\
\hline
\end{tabular}

TWO-DIMENSIONAL MODEL

The hydrological code used in the analysis is a two-dimensional finite element code developer by Taylor and Brown. ${ }^{2}$ The code calculates head, equipotentials, and flow vectors in problems governed by Darcy's equation under saturated steady-state conditions. Laplace's equation is solved, in each element, for two-dimensional flow in homogeneous anisotropic media (Eq. 2) :

$$
\frac{\partial}{\partial x}\left(k_{x} \frac{\partial h}{\partial x}\right)+\frac{\partial}{\partial z}\left(k_{z} \frac{\partial h}{\partial z}\right)=0
$$


where

$$
\begin{aligned}
& h=\text { hydraulic level } \\
& k=\text { hydraulic conductivity } .
\end{aligned}
$$

The 2-D model (Fig. 3) was designed to resolve the steady-state flow regime of the postexcavation physical model. The model incorporated 372 nodes with 346 elements positioned mainly around the depository, shaft and tunnel. The manmade fracture zones surrounding the depository and tunnel (Fig. 4) ware represented by the upper and lower strips of elements in the labeled regions. The element string sandwiched between the fracture zones was highly impermeable backifill $\left(\mathrm{K}=10^{-9} \mathrm{~cm} / \mathrm{s}\right)$. A similar arrangement was designed for the shaft. The hydraulic head potential values were distributed around the model boundary to correspond to the preexcavation hydrologic regime defined by the physical model. Table 2 contains the initial preferred values for hydraulic conductivity and porosity.

TABLE 2. The initial preferred values of hydraulic conductivity

\begin{tabular}{|c|c|c|c|}
\hline Feature & $\begin{array}{l}\text { K vertical, } \\
\mathrm{cm} / \mathrm{s}\end{array}$ & $\begin{array}{l}k \text { horizontal, } \\
\mathrm{cm} / \mathrm{s}\end{array}$ & Porosity \\
\hline Layers 2,6 & $10^{-5}$ & $10^{-4}$ & 0.1 \\
\hline Layers 3,5 & $10^{-7}$ & $10^{-6}$ & 0.05 \\
\hline Layer 4 & $10^{-9}$ & $10^{-8}$ & 0.01 \\
\hline Depository, nodes $1+2$ & 0.1 & 0.1 & 0.1 \\
\hline Tunnel, nodes $2+4$ & 0.1 & 0.1 & 0.1 \\
\hline $\begin{array}{l}\text { Shaft, nodes } 4+5+6 \\
\text { Depository bed, }\end{array}$ & $10^{-4}$ & $10^{-4}$ & $10^{-3}$ \\
\hline nodes $1 \rightarrow 3$ & $10^{-9}$ & $10^{-8}$ & 0.01 \\
\hline Barrier bed, nodes $3 \rightarrow 6$ & $10^{-7}$ & $10^{-6}$ & 0.05 \\
\hline Aquifer, nodes $6 \rightarrow 7$ & $10^{-5}$ & $10^{-4}$ & 0.1 \\
\hline
\end{tabular}
and porosity used in the $1-D$ and 2-D models. 


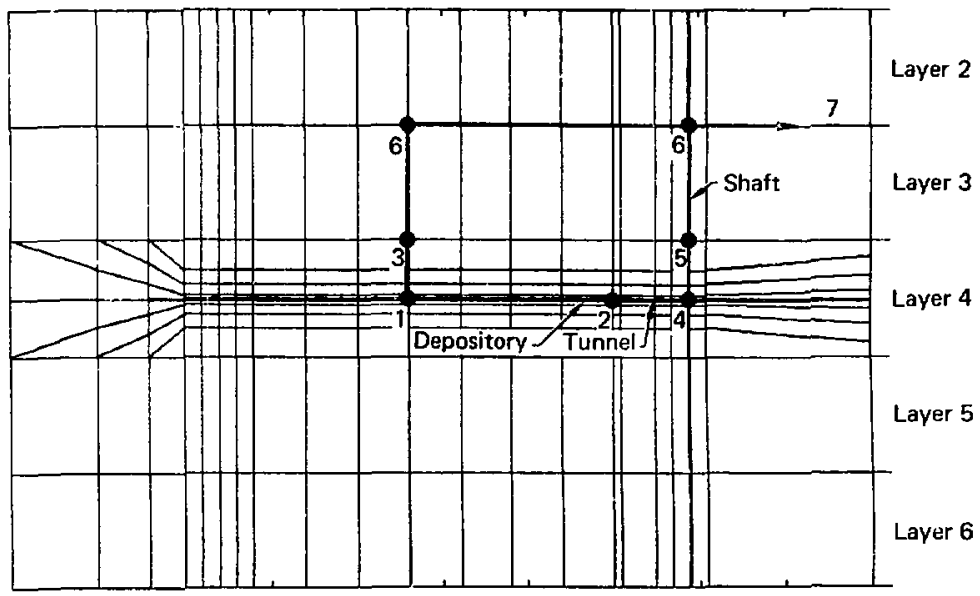

FIG. 3. The finite element mesh cross-sectional view with the 1-D node configuration superimposed. Note: The portion of the model containing the depository extends from 9000 to $14000 \mathrm{~m}$. 


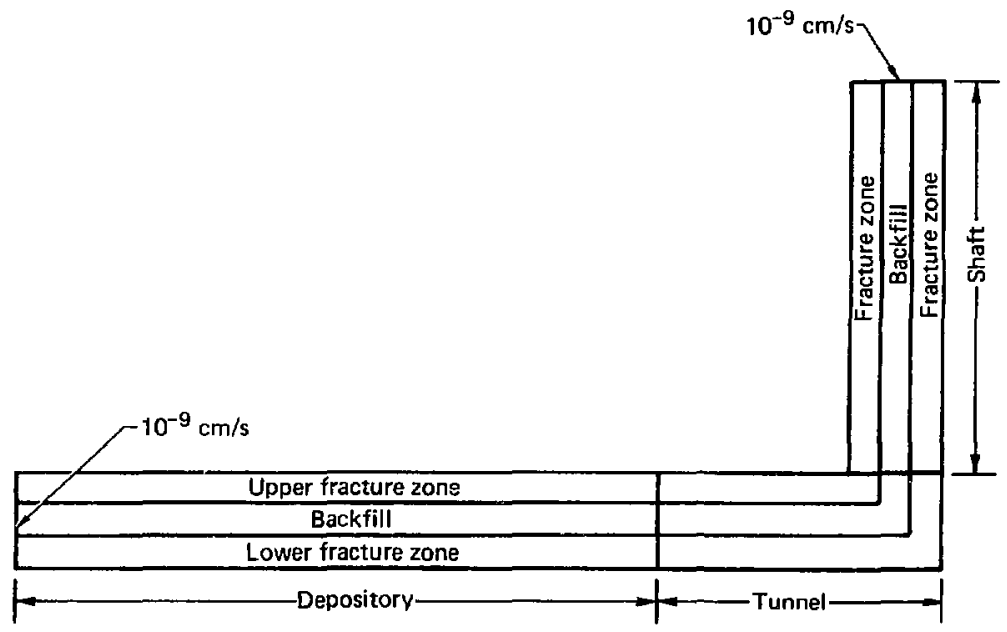

FIG. 4. The fracture zones surrounding the manmade feature represented by two layers of element strings above and below baclifill material. 
ANALYSIS

TWO-DTMFNSTONAL MODELS

Two sets of solutions were calculated with the 2-D models:

- The standard 2-D solutior.

- Solutions calculated when conductivity and porosity were scaled in accordance with flow path cross-sectional areas (identified as 2-D').

For 1-D to 2-D comparisons without scaling, the conductivities and porosities of equivalent features were the same. The following scaling procedures were used in comparisons of $1-D$ solutions to the 2-D' solutions having scaled conductivities and porosities. Flow through the depository and tunnel fracture zone is

$$
\begin{aligned}
& Q_{\text {dep }}=K_{\text {dep }} \frac{d h}{d l} A_{\text {dep }} \\
& Q_{\text {tun }}=K_{\text {tun }} \frac{d h}{d l} A_{\text {tun }}
\end{aligned}
$$

where

$$
\begin{aligned}
& Q=\text { flow } \\
& \mathbf{K}=\text { hydraulic conductivity } \\
& \frac{d h}{d l}=\text { head change/length of feature } \\
& A=\text { cross-sectional area. }
\end{aligned}
$$

To maintain continuity of flow

$$
K_{\text {dep }} \frac{d h}{d l} A_{\text {dep }}=K_{t u n} \frac{d h}{d l} A_{t u n} .
$$


Continuity exists in the 1-D model, but not in the $2-D$ model because of the inherent three-dimensionality of the problem. The 3-dimensional steady flow of fluid in a homogeneous anisotropic medium is governed by

$$
\frac{\partial}{\partial x}\left(k_{x} \frac{\partial^{h}}{\partial x}\right)+\frac{\partial}{\partial y}\left(k_{y} \frac{\partial^{h}}{\partial y}\right)+\frac{\partial}{\partial z}\left(k_{z} \frac{\partial^{h}}{\partial z}\right)=0 .
$$

Because the 2-D solution lacks the third dimension, $A_{d e p}$ and $A_{t u n}$ cannot be incorporated in the solution. However, the effect of the flow path cross-sections can be artifically imposed on the 2-D solution by scaling $k$, $\mathrm{K}_{\mathrm{z}}$, and porosity.

Of the manmade features, the depository had the largest cross-sectional area and it also extends the furthest into the plane of the model cross-section. Therefore, it is least affected by the absence of a third dimension flow solution. The depository was the feature from which the tunnel and shaft fracture zones were scaled. In the case of the depository,

$$
A_{\text {dep }}=z_{\text {dep }} \stackrel{a}{\text { dep }}
$$

where

$$
\begin{aligned}
A_{\text {dep }}= & \text { cross-sectional area of the depository fracture zone defined in } \\
& \text { the physical model } \\
z_{\text {dep }} & \text { height of the depository fracture zone defined by the finite } \\
& \text { element design } \\
a_{\text {dep }}= & \text { depth of the depository fracture zone into the third dimension. }
\end{aligned}
$$

In the case of the tunnel,

$$
A_{\text {tun }}=z_{\text {tun }} a_{\text {tun }}
$$


where

$$
\begin{aligned}
A_{\text {tun }}= & \text { cross-sectional area of the tunnel fracture zone as defined in } \\
& \text { the physical morel } \\
z_{\text {tun }}= & \text { height of the tunnel fracture zone defined in the finite element } \\
& \text { design } \\
d_{\text {tun }}= & \text { depth of the tunnel fracture zone into the third dimension. }
\end{aligned}
$$

The depth of: the depository ( $d_{\text {dep }}$ ' into the cross-sectional plane is

$$
d_{\text {dep }}=A_{\text {dep }} / z_{\text {dep }} \text {. }
$$

The depth of the tunnel is

$$
a_{\text {tun }}=A_{\text {tun }} / z_{\text {tun }}
$$

The scaliny factor for the tunnel ( $\left.\beta_{\text {tun }}\right)$ is

$$
B_{\text {tun }}=a_{\text {tun }} / d_{\text {dep }}
$$

The initial preferred $k$ value of the tunnel $\left(K_{i}\right)$ was scaled to a lower value (K) with

$$
\mathbf{k}_{\mathbf{s}}=\mathbf{k}_{\mathbf{i}} / \beta_{\text {tun }} \text {. }
$$

Porosities were similarly scaled.

ONE-DIMENSIONAL MODELS

In addition to the 1-D model, another one-dimensional model (1-D') was used in the comparisons. This model had the preferred values expressed in Table 2, but possessed larger cr:-s-sectional areas for the flow paths (Table 3). The 1-D' model was expected to yield results similar to those of $2-D$ and thereby create a basis for comparison. The large cross-sectional areas were calcL'ated by multplying the 2-D element height (z) of the depository and 
tunnel Exacture zone by 2 noo $m$ (which is the depth into the 2-D plane of the depository defined by the physical model and illustrated in Fig. 5). The same scaling procedure was applied to the shaft fracture zone. This technique was used to eliminate the effect of flow velocity increases due to constriction of cross-sectional areas of the tunnel and shaft (as in the 1-D). Thus, the 1-D' solutions were expected to be similar to the 2-D solution.

TABLE 3. Preferred cross-sectional areas (1-D) compared to modified (1-D') cross-sectional areas.

$\begin{array}{ccc} & \text { Fracture zone } & \text { Cross-section arma } \\ \text { Feature } & 1-D & 1-D^{\prime} \\ \mathrm{m}^{2} & \mathrm{~m}^{2}\end{array}$

Depository, aodes $1+2$

316

23000

Tunnel, nodes $2 \rightarrow 4$

18.96

23000

shaft in depository bed,

nodes $4+5$

10

8000

Shaft in upper barcier

bed, nodes $5+6$

5

8000

Layers 3 and 4 above the

depository, nodes $1+3+6$

$5 \times 10^{6}$

$5 \times 10^{6}$

Layer 2 , nodes $6+7$

$4 \times 10^{6}$

$4 \times 10^{E}$ 


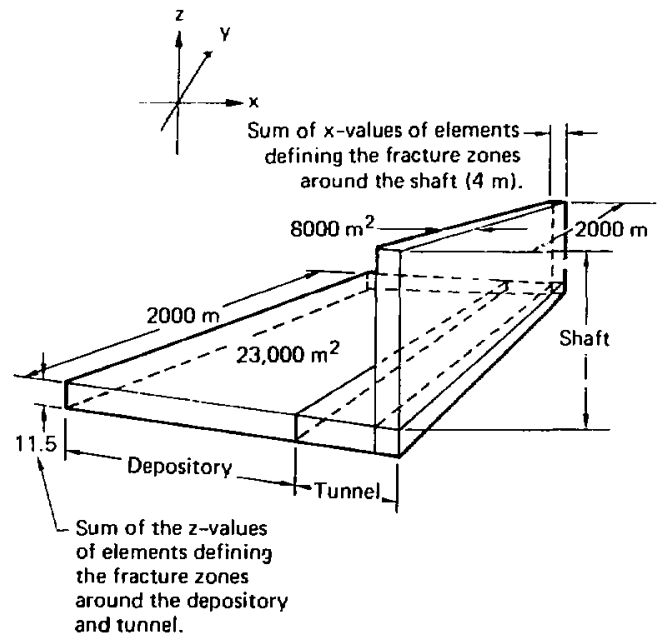

FIG. 5. Large cross-sectional areas of $1-D^{\prime}$ calculated from $x$ and $z$ values of 2-D and $y$ values of the physical model. 
For display purposes equal potentials were confined between $9000 \mathrm{~m}$ and $14000 \mathrm{~m}$. The preexcavation flow sy3tem for the 2-D analysis was calculated to satisfy the physical model specifications for steady-state conditions (Fig. ()); potentials were contoured with 25 equal intervals in all studies. This established the boundary conditions of the 2-D model.

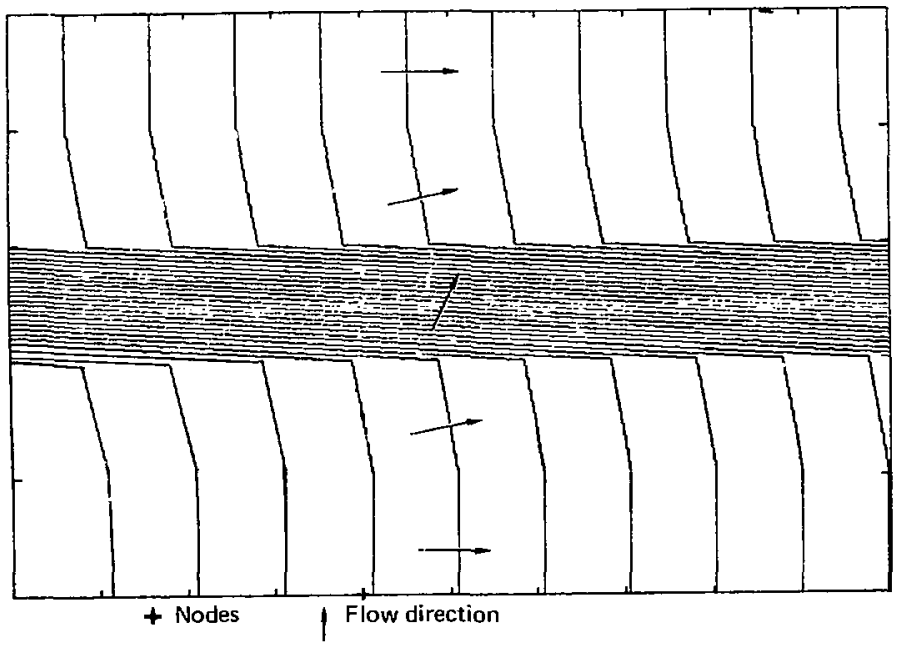

FIG. 6. Equipotentials of the steady-state ground-water system in the preexcavation state. Note: Potentials were contoured with 25 equal intervals.

The postexcavation flow regime is most sensitive to the conductivity of the fracture zones surrounding the manmade features. To compare variations in the results between the four solutions $\left(1-D, 2-D, 1-D^{\prime}, 2-D^{\prime}\right)$, the $k$ values of the fracture zones were varied by five ordezs of magnitude (Table 4 ) to produce trends in emergence times of marker particles. 
TABLE 4. Hydraulic conductivitiesi assigned to the fracture zones surrounding the depository, tunnel, and shaft.

\begin{tabular}{ccc}
$\begin{array}{c}\text { Simulation } \\
\text { number }\end{array}$ & $\begin{array}{c}\text { Depository and turinel } \\
\text { fracture zone, cm/s }\end{array}$ & $\begin{array}{c}\text { Shaft fracture } \\
\text { zone, cm/s }\end{array}$ \\
\hline 1 & 10 & $10^{-2}$ \\
2 & 1 & $10^{-3}$ \\
3 & 0.1 & $10^{-4}$ \\
(preferred values) & $10^{-2}$ & $10^{-5}$ \\
4 & $10^{-3}$ & $10^{-6}$ \\
\hline
\end{tabular}

Bulk velocities obtained from model calculations were cunverted to pore velocities by ${ }^{3}$

$$
v_{i}=\frac{v_{m}}{E} \text {, }
$$

where

$$
\begin{aligned}
& v_{i}=\text { pore velocity } \\
& v_{\pi}=\text { bulk velocity } \\
& \varepsilon=\text { porosity. }
\end{aligned}
$$

In scaled $K$ analysis, $\varepsilon$ was also scaled with $\beta$ to maintain continuity of Elow.

The measure used to compare the performance of the models was the travel time of a nonreacting marker particle moving between the nodal locations of the 1-D mode1. Travel times in the 2-D model were calculated from the velocity vectors corresponding to the 1-D eirection. In some cases, a comparison was impossible (e.g., in the case of high conductivity in the depository fracture zones of $2-D$ and $\left.2-D^{\prime}\right)$. The fracture zone became a grourit-water sink that caused downward flow above the depository. In all cases, the flow direction was upward between nodes 1,3 , and 6 of the 1-D model. However, the fracture 
zones in the 1-D model were represented by elements approximately 100 times thicker than those prescribed by the physical model. When the fracture zone conductivity was incrementally decreased (Figs. 7, B, 9), the flow direction approached the 1-D solution. The sink effect also occurred in the scaled $K$ cases, but to a lesser extent because flow to the upper aquifer (via fracture zones) was constricted by scaled-down $\mathrm{K}$ values around the tunnel and shaft. The appendix contains the complete 2-D sequence of equipotential plots of decreasing conductivity exhibited in the fracture zones.

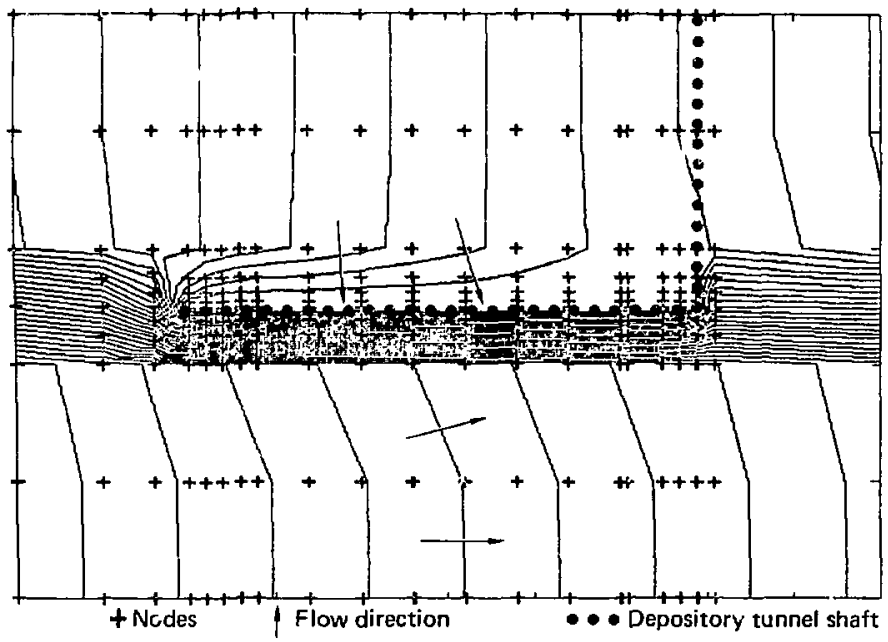

FIG. 7. Equipotentials of the steady-state flow regime (2-D) when $k$ of the depository and tunnel fracture zones $=0.1 \mathrm{~cm} / \mathrm{s}$ and $\mathbf{k}$ of the shaft fracture zones $=10^{-4} \mathrm{~cm} / \mathrm{s}$. Note: Potentials were contoured with 25 equal intervals. 


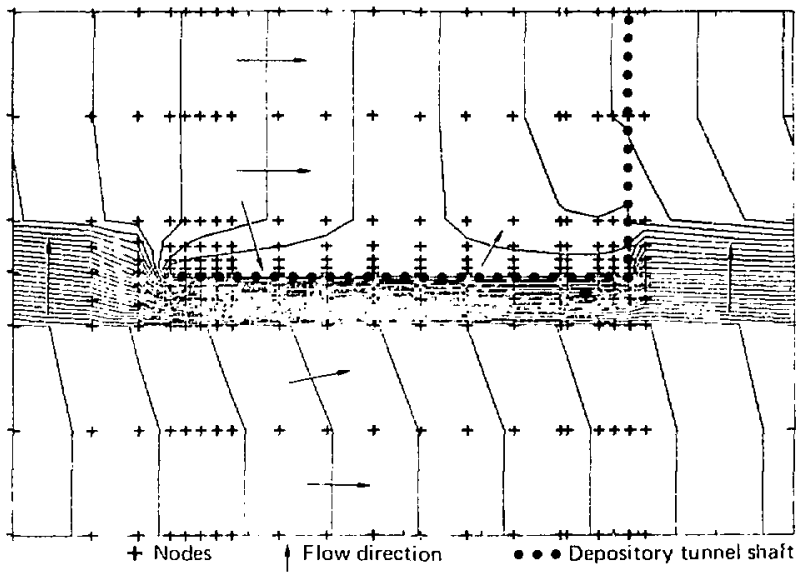

FIG. 8. Equipotentials of the steady-state flow regime (2-D) when $K$ of the depository and tunnel fracture zone $=0.01 \mathrm{~cm} / \mathrm{s}$ i. .J $\mathrm{K}$ of the shaft $=$ $10^{-5} \mathrm{~cm} / \mathrm{s}$. Note: Potentials were contoured with 25 equal intervals.

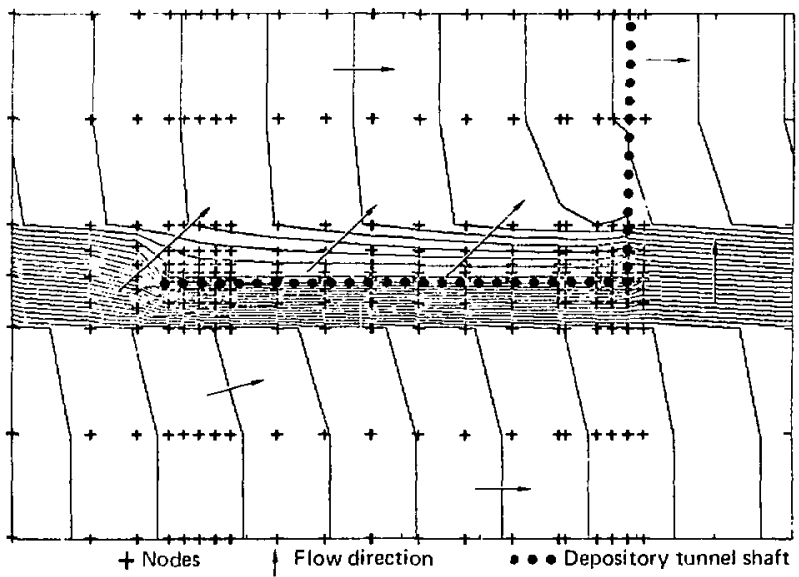

FIG. 9. Equipotentials of the steady-state flow regime (2-D) when $K$ of the depository ind tunnel fracture zones $=10^{-2} \mathrm{~cm} / \mathrm{s}$ and $\mathrm{K}$ of the shaft fracture zones $=10^{-5} \mathrm{~cm} / \mathrm{s}$. Note: Potentials were contoured with 25 equal intervals. 
Travel times were plotted against conductivities for 4 solutions: 1-D, 1-D' (large cross-sectional areas), 2-D, and 2- $D^{\prime}$ (scaled $K$ and $E$ ). One plot was produced for each flow path segment defined by the 1-D model (Figs. 10-14).

The techniques compare well with respect to travel time thiough the depository fracture zone between nodes 1 and 2 , particularly at the preferred value (Fig. 10).

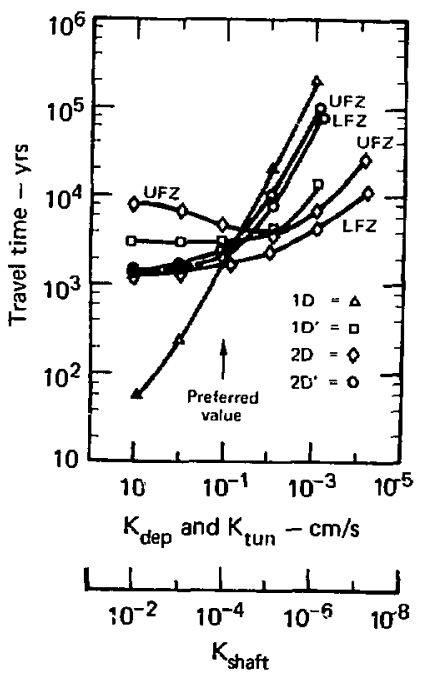

FIG. 10. Flow through the depository fracture zone between nodes 1 and 2 . 


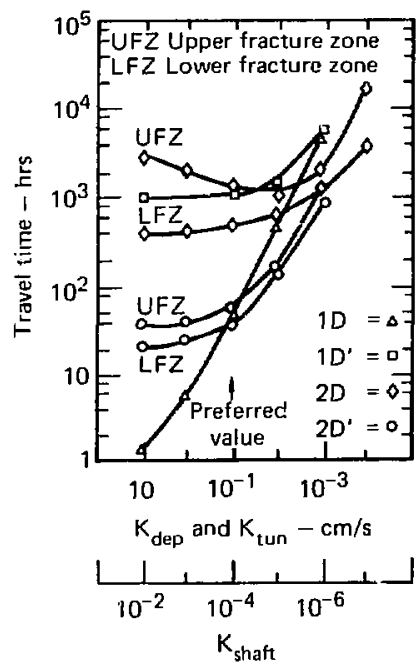

FIG. li. Flow through the tunnel fracture zone between nodes 2 and 4 .

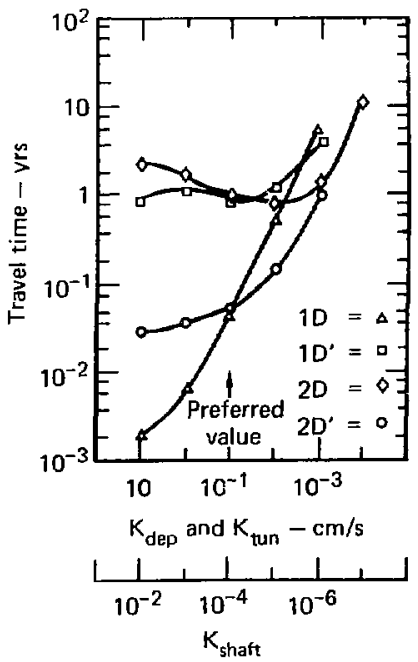

EIG 12. Flow through the shaft fracture zone in the depository bed between nodes 4 and 5 . 


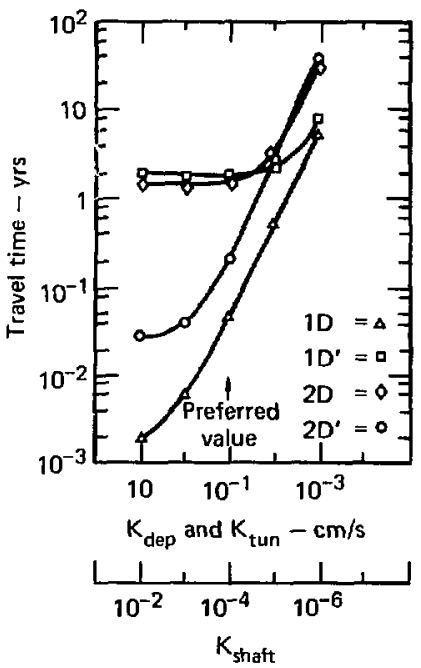

FIG. 13. Flow through the shaft iracture zone in the barrier bed between nodes 5 and 6 .

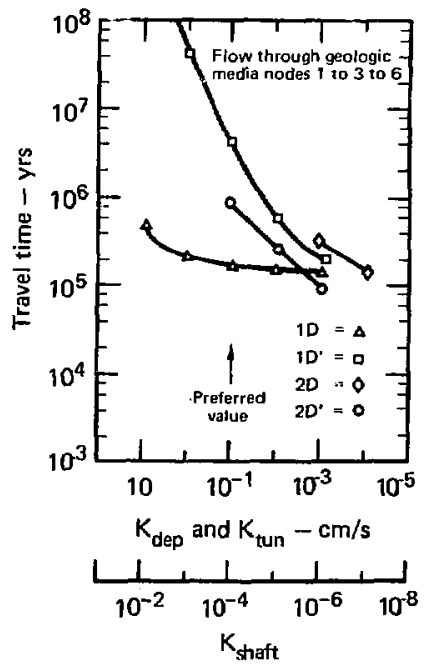

FIG. 14. Flow through the geologic media above the depository between nodes 1,3 , and 6 . 
At higher conductivities, the $1-D$ model is far more conservative yielding shorter travel times. However, at lower conductivities, 1-D is less conservative. The relationship of $K$ to travel time is linear (from Darcy's equation).

The divergence of both 2-D and 2-D' from 1-D reflects, in part, the lack of interaction of 1-D with the surrounding media. The head difference between the fracture zone and the surrounding media causes flow in addition to that moving in the $\mathrm{I}-\mathrm{D}$ directior. When $\mathrm{K}_{\mathrm{dep}}=10 \mathrm{~cm} / \mathrm{s}$ and $\mathrm{K}_{\text {shaft }}=10^{-2} \mathrm{~cm} / \mathrm{s}$, water table conditions in 2-D are created by dissipation of the preexcavation

-tesian head above the depository. Because of this, travel time changes little at high $\mathrm{K}$ values. When $\mathrm{K}_{\text {dep }}=10^{-2} \mathrm{~cm} / \mathrm{s}$ and $\mathrm{K}_{\text {shaft }}=10^{-5} \mathrm{~cm} / \mathrm{s}$, the artesian head above the depository is restored. At $\mathrm{K}_{\mathrm{dep}}=0.1 \mathrm{~cm} / \mathrm{s}$ and $K_{\text {shaft }}=10^{-4} \mathrm{~cm} / \mathrm{s}$, the 2-D' fracture zones contain sufficient head to maintain the artesian head above the depository; scaling down of $K$ in the shaft contains the head within the depository.

Model 1-D', at hydraulic conductivities greater than the prefierred values, exhibits ro change in travel time. The large cross-sectional areas and high $\mathrm{K}$ values used in 1-D' dissipate the artesian head. At lower conductivities, the head is restored throughout the system and, as in 1-D, travel time becomes a function of $\mathrm{k}$.

Inspection of the solutions for node 1 to node 2 yield the following conclusions:

- The 2-D solution contributes some insight to the sensitivity of the system to $\mathrm{K}_{\text {dep' }}$ under 2-D assumetions.

- The 2-D' scaling technique approaches a 3-D solution, but the resul's have yet to be tested by a 3-D model.

- The 1-D' model approaches the 2-D solution and may single out the effest caused by interaction with surrounding media.

The travel times between nodes 2 and 4 (Fig. 11) reflect the calculated flow between nodes 1 and 2 . At the preferred $k$ values, the solutions form two groups: 
- Those attempting to conserve flow (1-D and 2-D').

- Those with large cross-sectional areas (2-D and 1-D'). The solutions conserving flow have shorter travel times than the 1-D' and 2-D solutions.

In the case of $1-D$, travel time has been greatly reduced because the distance between 2 and 4 is only $36 \%$ of the distance between $I$ and 2 and because the cross-sectional area has decreased 948 from $316 \mathrm{~m}^{2}$ to $18.96 \mathrm{~m}^{2}$. Velocity must increase to conserve flow in a constrlcted segment. For this reason, the reduced pseudo-cross-sectional area in 2-D' causes higher velocities.

Models 2-D and I-D' have large cross-sectional areas and velocities are slower than in the flow conserving solutions. In the 2-D solutions, the lower fracture zone is always under greater head than the upper fracture zone. In 1-D', travel times are unaffected, except at the lowest $K$ values.

The travel time from segment 4 to $5(100 \mathrm{~m})$ is less than 15 years for al] solutions, at all conductivities. From node 4 to 5 the solutions form two groups as above. The $K$ vs travel time curves between nodes 4 and 5 (Fig. 12) represent the same phenomena seen between nodes 2 and 4 in Fig. 11 .

The travel time for all solutions between nodes 5 and $6(200 \mathrm{~m})$ was less than 45 years (Fig. 13). In this segment, the 2 groups of solutions persist; when flow is conserved, the $\mathrm{K}$ to travel time relationship is linear.

In all solutions, the combined travel times between nodes 1 and $6(1+3+6)$ are greater than $10^{5}$ years (Fig. 14). Above the depository, upward velocities are created by transmission of the artesian head through the depository and tunse i iracture zones. The negative slopes of the curves (Fig. 14) reflect higher upward velocities in the strata when the conductivity of the depository, tunnel and shaft is Iow. The 2-D and 2-D' curves are discontinuous at the higher $\mathrm{R}$-values because flow is downard.

The length of the segment $6+7$ is $16000 \mathrm{~m}$; the travel time for all solutions is $10^{4}$ years. 


\section{CONCLUSIONS AND RECOMMENDATIONS}

\section{CONCLUSIONS}

The solutions of the flow-conserving models ( $1-D$ and 2-D') compare well with each other as do solutions 2-D and 1-D'. This statement is based on the relationships between travel time plots.

In general

- The 1-D and the 2-D solutions can only approximate the irue flow regime. Therefore, only statements about relationships between the model solutions are warranted.

- Because of the inherent three-dimensionality of the problem, oniy a 3-D model can precisely describe the flow system. The 3-D solution is a standard to which lower order models can be compared.

- Flow-conserving solutions have greater flow velocities and shorter travel times for marker particles than do 2-D solutions. The estimates of travel times derived from the $1-D$ and $2-D^{\prime}$ solutions are conservative in that the travel times they yield are shorter.

\section{RECOMMENOATIONS}

The 3-D flow system of the depository model should be calculated. The standard established by the 3-D solution will permit an individual quantitative evaluation of each solution set. The trends found in this comparison can then be examined quantitatively. 


\section{ACKNOWLEDGMENTS}

The writer wishes to particularly thank T. F. Harvey for his technical assistance in applying this method. The support of G. D. Mendez, L. D. Thorson, D. Isherwood, and S. Dreiss is also gratefully acknowledged. The writer also wishes to thank R. Stone and D. F. Towse for helpful suggestions in preparing this manuscript. 


\section{REFERENCES}

1. N. L. Dayem, T. Holdsworth, D. F. Towse, D. Isherwood, and R. A. Heckman, NRC StaEf, Sito Suitability Criteria for Solidified High Level waste Repositories, Lawrence Livermore Laboratory, Livermore, Calif., UCID-17831 (1977).

2. R. L. Taylor and C. B. Brown, "Darcy's Flow Solutions with a Free Surface", in Pruc. Anerican Society of Civil Engineers, Journal of Hydraulics Division, Vol. 93, No. HY2, pp. 25-33 (1967).

3. P. A. Domenico, Concepts and Models in Ground-Water Hydrology (McGraw-Hill, New York, 1972), p.405. 


\section{APPENDIX}

This appendix contains a sequence of 2-D' equipotential plots in which the conductivity of the man-made fracture zones is incrementally decreased.

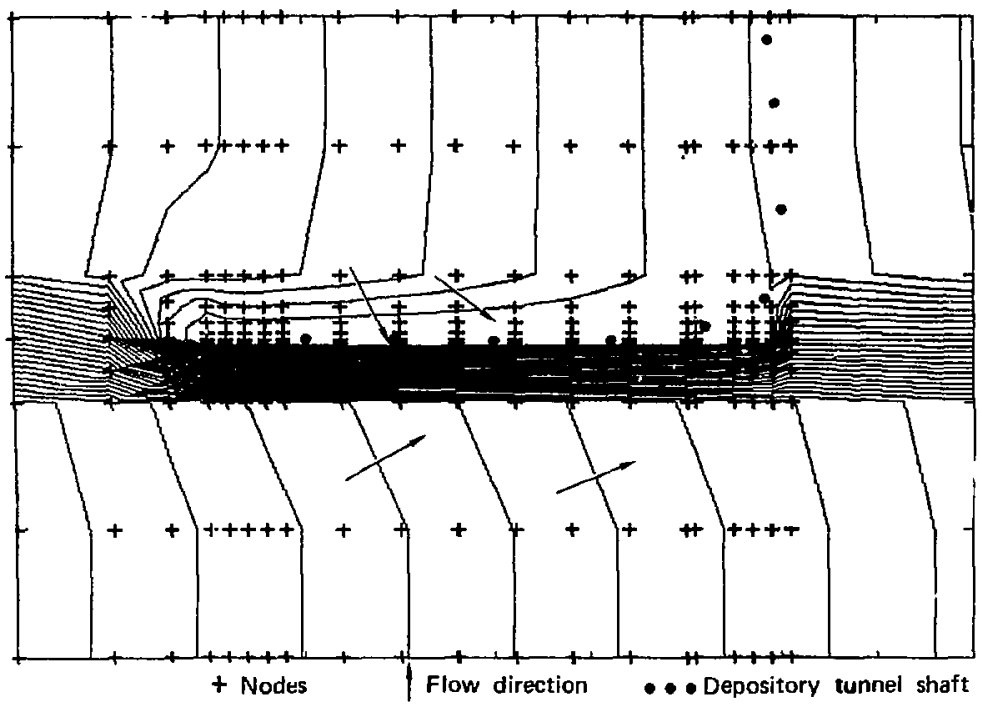

A-1. The conductivities of the fracture zones are 100 times greater than the preferred yalues. 


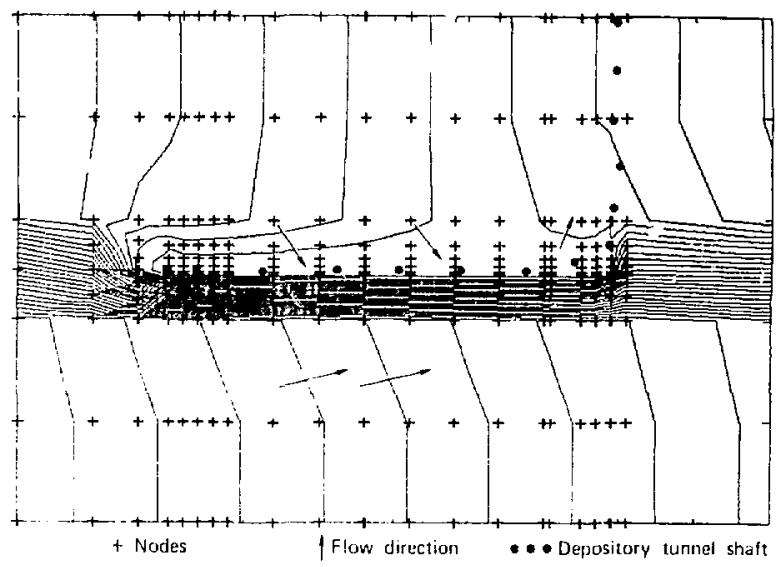

A-2. The conductivities of the fracture zones are 10 times greater than the preferred values.

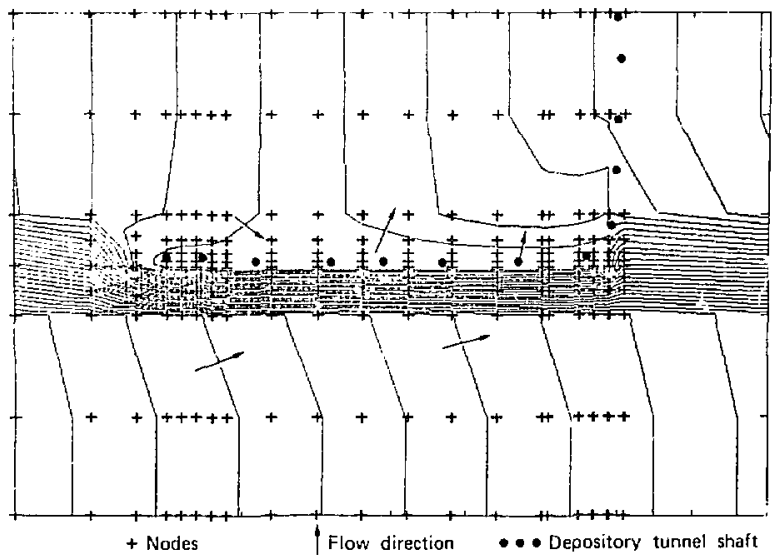

A-3. The conductivities of the fracture zones egial the preferred values. 


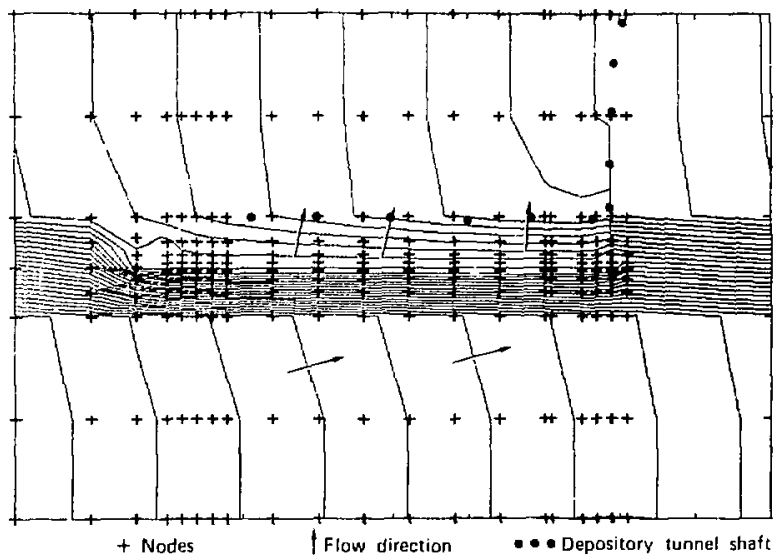

A-4. The conductivities of the fracture zones are 10 times less than the preferred values (2-D').

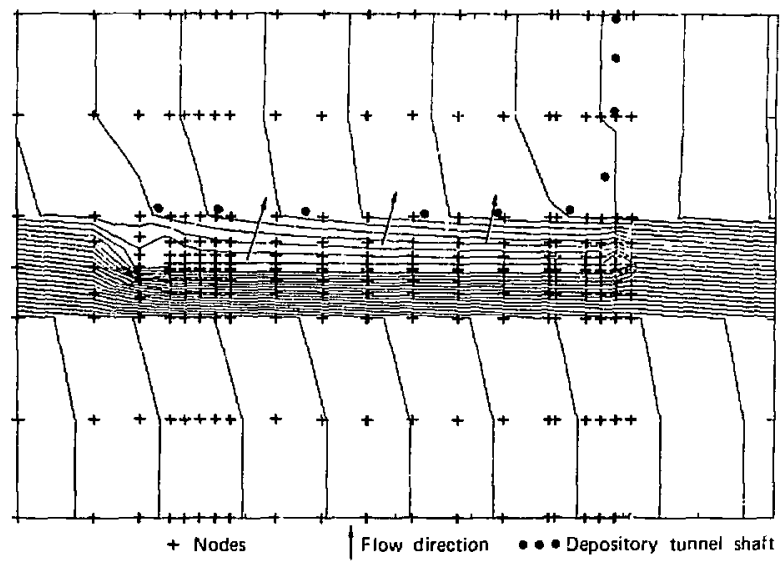

A-5. The conductivities of the fracture zones are 100 times less than the preferred values $\left(2-D^{\prime}\right)$. 